\title{
Numerical simulation analysis on the flexural behaviors of ECC-RC composite beams reinforced with high strength steel bars
}

\author{
GE Wenjie ${ }^{a^{*}}$, Huo Zhengdong ${ }^{b}$, Gui Changqing ${ }^{c}$, Yang Ming ${ }^{d}$ \\ College of Civil Science Engineering, Yangzhou University, Yangzhou 225127, China \\ agewj@yzu.edu.cn, b2433240086@qq.com, '841245380@qq.com, d963797840@qq.com
}

Keywords: high strength steel bars, concrete, ECC, composite beams, flexural behaviors

\begin{abstract}
Based on the simplified material constitutive model and strip analysis method, computer program languages is used to analysis the flexural behaviors of ECC-RC composite beams reinforced with high strength steel bars. The results show that cracking, yield and ultimate moment increase with the increasing of height replacement rate and the increasing rate gradually slow down. Yield and ultimate moment increase with the increasing of reinforcement ratio or reinforcement strength. The stiffness of ECC-RC composite beams essentially unchanged after the cracking of ECC.
\end{abstract}

\section{Introduction}

The steel stress level of concrete flexural component reinforced with high strength steel bars is higher than RC beams reinforced with normal strength steel bars, tensile concrete quit working after cracking components occurs larger cracks and deformation [1], under the coupling action of load and environmental erosion, concrete strength and steel bars cross-section area decreases, the flexural capacity decrease correspond and the components do not meet the requirement of ultimate limit state. Maalej [2] propose using engineered cementitious composite (ECC) take place the tensile concrete around the longitudinal tensile reinforcement (as shown in figure 1). The results shows that compared with normal RC beam, flexural capacity and deformation ability of composite beam improve, but the amplitude is small. But before the yield of steel bars, crack width is less than $0.05 \mathrm{~mm}$, just $1 / 5$ of the normal RC beams. Feng [1] think that the effect of waterproof, corrosion resistance and the influence of the bearing capacity could neglect when the crack width is less than $0.05 \mathrm{~mm}$. Therefore, the use of ECC can greatly improve the durability of RC beam. Xu [3-4] analyzed the basic theory of bending crack resistance of ECC-RC composite beams.

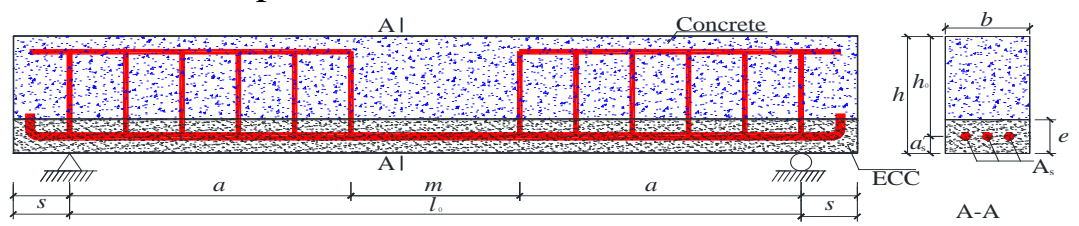

Fig.1 Schematic diagram of ECC-RC composite bending beams reinforced with steel bars

Research on the flexural behaviors of ECC-RC composite beams is still lack at home and abroad. Based on the simplified material constitutive model and strip analysis method, computer programming languages is used to analysis the flexural behaviors of ECC-RC composite beams reinforced with high strength steel bars in this article.

\section{Section Force Analysis}

As shown in figure 2, rectangular section reinforced concrete members under the action of eccentric axial force $N$ or under the joint action of the axial force $N$ and the bending moment $M=\mathrm{Ne}_{0}$ , section of the strain, stress distribution and the balance of the section force. This strain and stress distribution is suitable for the state from the beginning to the overall process to achieve ultimate load [5]. 


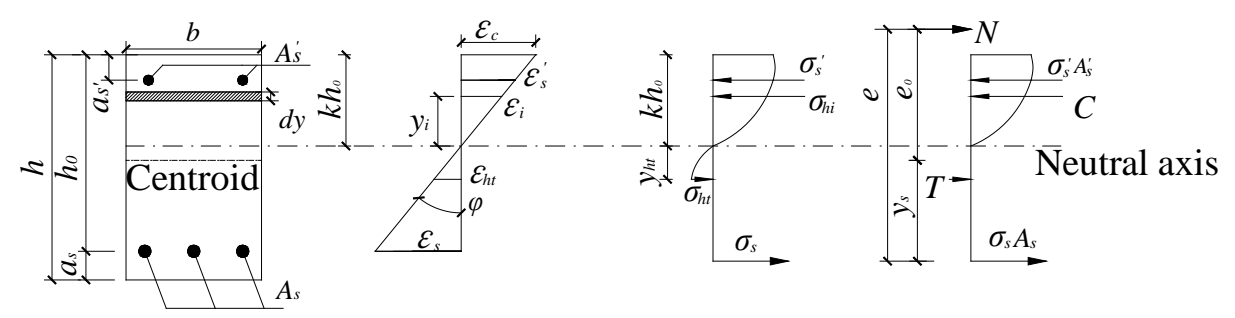

Fig.2 Strain and stress distribution of rectangular cross-section

If the stress-strain relationship of concrete is known for continuous function, force equilibrium equations could be expressed as follows.

$$
\begin{gathered}
b \int_{0}^{k h_{0}} \sigma_{h}\left(\varepsilon_{h}\right) d y+A_{s}^{\prime} \sigma_{s}^{\prime}-b \int_{0}^{y_{h t}} \sigma_{t}\left(\varepsilon_{h t}\right) d y-A_{s} \sigma_{s}=N \\
b \int_{0}^{k h_{0}} \sigma_{h}\left(\varepsilon_{h}\right)\left(h_{0}-k h_{0}+y\right) d y+A_{s}^{\prime} \sigma_{s}^{\prime}\left(h_{0}-a_{s}^{\prime}\right)-b \int_{0}^{y_{h t}} \sigma_{t}\left(\varepsilon_{h t}\right)\left(h_{0}-k h_{0}-y\right) d y=N\left(y_{0}+e_{o}\right)
\end{gathered}
$$

\section{Material constitutive models}

The accuracy of numerical simulation analysis results of RC structures largely depends on the adopted material constitutive model. Since the analysis is limited to plane problem of nonlinear analysis, so material constitutive could use uniaxial stress state. Concrete compressive stress-strain relationship [6] is shown in figure 3. Constitutive model of steel is shown in figure 4; simplify compressive and tensile stress-strain curves of ECC [7] are shown in figure 5 and figure 6.

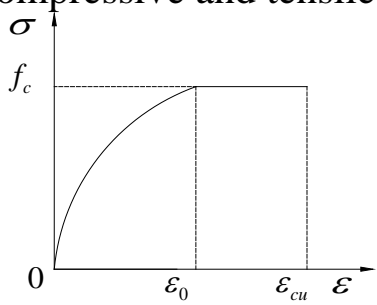

Fig.3 Concrete-compressive

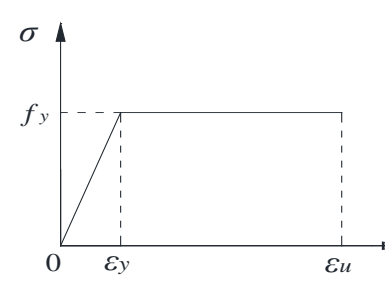

Fig.4 steel bar-tensile

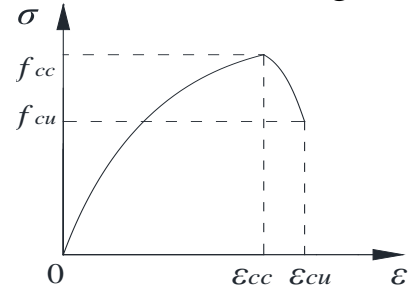

Fig.5 ECC- compressive

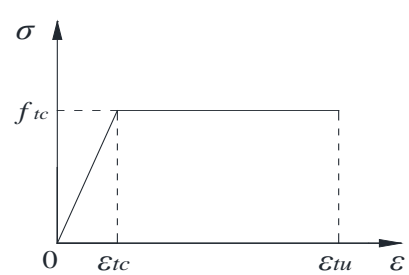

Fig.6 ECC- tensile

\section{Numerical iteration methods}

For flexural component, section of the bending moment-curvature of iterative calculation can be calculated according to the following steps: 1) Take curvature $\varphi:=\varphi+\Delta \varphi$ every time; 2) Assume a certain section of the strain $\varepsilon_{\mathrm{c}}$; 3) Determine the strain $\varepsilon$ of each strip; 4) Obtained stress $\sigma$ which is corresponding to the strain $\varepsilon$ according to the stress-strain relationship of steel and concrete; 5) Add up to internal force of each strip and made a test whether meet the equilibrium condition of cross section; 6) Modify the assumed $\varepsilon_{\mathrm{c}}$ and repeat (c) (e) if the condition not satisfied; 7) After the equilibrium conditions is satisfy, corresponding internal moment $M$ can be obtained ; 8) Repeat (1) (7) and repeated cycle calculation. After obtained the $M-\varphi$ corresponding relationship, it is not difficult to use numerical integral to calculate any point deflection of components.

\section{Parameter analyses}

Basic parameters. Specimen size $b \times h \times l=150 \mathrm{~mm} \times 200 \mathrm{~mm} \times 1500 \mathrm{~mm}$. C35 fine aggregate concrete was used, protective thickness of longitudinal reinforcement is $20 \mathrm{~mm}, f_{c k}=23.4 \mathrm{~N} / \mathrm{mm}^{2}$, $f_{\mathrm{c}}=16.7 \mathrm{~N} / \mathrm{mm}^{2}, f_{\mathrm{tk}}=2.2 \mathrm{~N} / \mathrm{mm}^{2}, f_{\mathrm{t}}=1.57 \mathrm{~N} / \mathrm{mm}^{2}, E_{\mathrm{c}}=31.5 \times 10^{3} \mathrm{~N} / \mathrm{mm}^{2}$. Diameter of $12 \mathrm{~mm} \mathrm{HRB335}$ steel bars were used, $f_{\mathrm{yk}}=335 \mathrm{~N} / \mathrm{mm}^{2}$; Diameter of $12 \mathrm{~mm}$ HRB500 steel bars were used, $f_{\mathrm{yk}}=500$ $\mathrm{N} / \mathrm{mm}^{2}$; Diameter of $12 \mathrm{~mm}$ and $10 \mathrm{~mm}$ HRB400 steel bars were used as longitudinal reinforcement, $f_{\mathrm{yk}}=400 \mathrm{~N} / \mathrm{mm}^{2}$, Diameter of $8 \mathrm{~mm}$ HRB400 steel bars were used as stirrups, $f_{\mathrm{yk}}=400 \mathrm{~N} / \mathrm{mm}^{2}$, 
$E_{\mathrm{s}}=200 \times 10^{3} \mathrm{~N} / \mathrm{mm}^{2}$. Material strength standard values were adopted in the numerical simulation. Specimen design parameters are shown in table 1.

Table 1 Specimen design parameters

\begin{tabular}{ccccc}
\hline number & longitudinal steel & stirrup & erection bars & height replacement rate $r_{\mathrm{h}}$ \\
\hline ESA & $2 \Phi 12$ & $\$ 8 @ 125$ & $2 \$ 10$ & $0 / 0.25 / 0.5 / 0.75 / 1.0$ \\
ESB & $1 \$ 10$ & $\$ 8 @ 250$ & $2 \$ 10$ & $0 / 0.25 / 0.5 / 0.75 / 1.0$ \\
ESC & $1 \$ 12$ & $\$ 8 @ 250$ & $2 \$ 10$ & $0 / 0.25 / 0.5 / 0.75 / 1.0$ \\
ESD & $2 \$ 10$ & $\$ 8 @ 125$ & $2 \$ 10$ & $0 / 0.25 / 0.5 / 0.75 / 1.0$ \\
ESE & $2 \$ 12$ & $\$ 8 @ 100$ & $2 \$ 10$ & $0 / 0.25 / 0.5 / 0.75 / 1.0$ \\
ESF & $2 \$ 12$ & $\$ 8 @ 100$ & $2 \$ 10$ & $0 / 0.25 / 0.5 / 0.75 / 1.0$ \\
\hline
\end{tabular}

Note: $\Phi$, HRB335 grade steel bar; $\Phi$, HRB400 grade steel bar; $\Phi$, HRB500 steel bar.

Crack moment.The relationship curves of cracking moment and the height replacement rate are shown in figure 7.

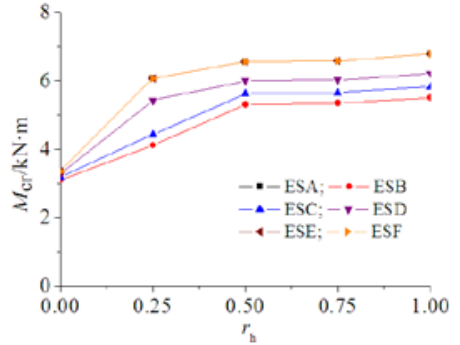

Fig.7 Curves of cracking moment and height replacement rate

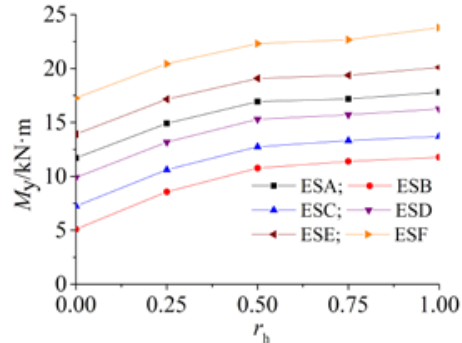

Fig. 8 Curves of yield moment and height replacement rate

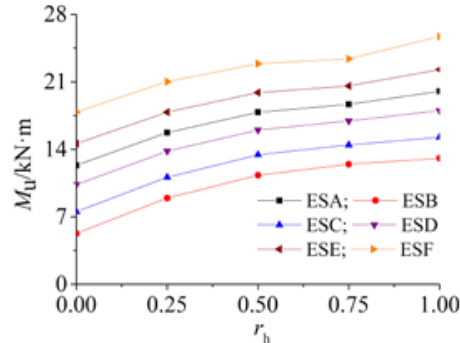

Fig.9 Curves of ultimate moment and height replacement rate

As can be seen from the figure, crack moment increase with the increasing of height replacement rate and the increasing rate gradually slow down; The group of ESA, ESE, ESF specimen crack moment are the same when replacement height are the same, that is specimen have the same crack moment while their reinforcement ratio is the same; Crack moment of group ESA is the minimum when replacement height are the same, group ESB is larger than it, group ESC has improved when compare with group ESB, group ESA, ESE and ESF is the largest when replacement height are the same, that is crack moment increase with the increasing of reinforcement ratio.

Yield moment and ultimate moment.The relationship curves of yield moment, ultimate moment and the height replacement rate are shown in figure in figure 8 and 9. The figure shows that the yield and ultimate moment increase with the increasing of height replacement rate and the increasing rate gradually slow down; Yield and ultimate moment changed from small to big followed by ESB, ESC, ESD, ESE when height replacement rate and reinforcement strength homogeneous are the same, that is yield and ultimate moment increase with the increasing of reinforcement ratio; Yield and ultimate moment changed from small to big followed by ESA, ESD, ESF when height replacement rate and reinforcement ratio homogeneous are the same, that is yield and ultimate moment increase with the increasing of the strength grade of steel bars.

Mid-span load-deflection curves. Curves of mid-span load-deflection are shown in figure 10.
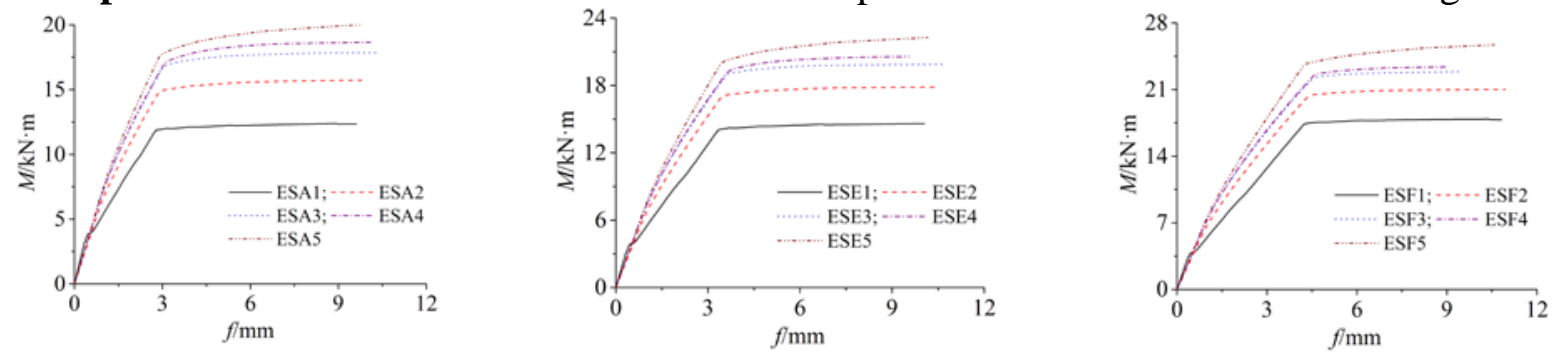

Fig.10 Partly specimen mid-span load-deflection curve

As can be seem from figure 10, load-deflection curve of composite beam can be divided into two sections. First, from begin load until the yield of steel bars. Stiffness of RC specimen drops large after the cracking while stiffness of ECC-RC composite beam essentially unchanged after the cracking of ECC. Second, from the yield of steel bars to the damage of specimen, the phenomena of ECC-RC 
composite beams is the same with reinforced concrete beam, specimen deflection increase greatly while the load is increased slightly. Depending on the strength grade of steel bars, reinforcement area and the distribution of the replacement rate, there are two composite beam failure modes, steel breaking or concrete crushing, specimen ESA4, ESE3, ESE4, ESF2, ESF3, ESF4 failure mode are concrete crushing, others specimen failure modes are steel breaking. Because the reinforcement ratio is low, damage model of all ECC beams are the breaking of reinforced bars.

\section{Conclusions}

(1) Crack moment increase with the increasing of height replacement rate and the increasing rate gradually slow down; Crack moment increase with the increasing of reinforcement ratio, specimen have the same crack moment while their reinforcement ratio is the same.

(2) Yield and ultimate moment increase with the increasing of height replacement rate and the increasing rate gradually slow down; Yield and ultimate moment increase with the increasing of reinforcement ratio and the strength grade of steel bars.

(3) Stiffness of RC specimens drop large after the cracking while the stiffness of ECC-RC composite beam essentially unchanged. With the different of the strength grade of materials, reinforcement ratio and height replacement rate, there are two failure modes of composite beams, reinforcement break or concrete crush.

\section{Acknowledgments}

The authors appreciate the support of the national natural science foundation of China (51308490), the natural science foundation of Jiangsu province, China(BK20130450), the science and technology projects of ministry of housing and urban-rural development (2013-K4-17), the natural science foundation for colleges and universities in Jiangsu province (13KJB560015), the science and technology projects fund of Yangzhou city (2012149), the open foundation of southeast university, key laboratory of concrete and pre-stressed concrete structure of ministry of education, the Jiangsu government scholarship for overseas studies, students' academic technology innovation fund project, Yangzhou university (x2015500).

\section{References}

[1] Feng Naiqian,Gu Qingxia, Hao Tingyu. The crack and countermeasures of the concrete structure [M]. Beijing: China Machine Press, 2006.

[2] Maalej M, Li VC. Introduction of strain-hardening engineered cementitious composites in design of reinforced concrete flexural members for improved durability [J]. ACI Structural Journal, 1995, 92(2): 167-176.

[3] Xu Shilang, Wang Nan, Li Qinghua. Experimental study on the flexural performance of concrete beam strengthened with ultra-high toughness cementitious composites [J]. China civil engineering journal, 2010, 43 (5): 17-22.

[4] Zhang Xiufang, Xu Shilang, Li Hedong. Theoretical analysis of flexural performance of plain concrete beams strengthened with ultra-high toughness cementitious composites [J]. China civil engineering journal, 2010, 43 (7): 51-62.

[5] Gu Xianglin, Sun Feifei. Computer simulation of concrete structure. Shanghai: Tongji University Press, 2002

[6] Lan Zongjian, Liang Shuting, Meng Shaoping . Design Philosophy Concrete Structure [M]. Nanjing: Southeast University Press, 2002 
[7] Li V C, Wang S, Wu C. Tensile strain-hardening behavior of PVA-ECC [J]. ACI Journal of Materials, 2001, 98(6): 483-492. 